\title{
Algumas reflexões em torno da utilização de paisagens em atividades escolares: descrição e análise de um caso prático
}

\author{
Juliano de O liveira Guterres* \\ $M$ arcelo L eandro Eichler** \\ J osé C laudio D el Pino***
}

\begin{abstract}
R esumo: Este artigo tem relação com um projeto pedagógico que visa a uma abordagem dos conhecimentos fundamentais à química a partir das geociências. U ma das atividades didáticas desenvolvidas no escopo desse projeto pedagógico utiliza imagens de paisagens naturais com a intenção de motivar e articular a discussão entre alunos e professores sobre diversos fenômenos físicos e químicos. $O$ presente artigo traz algumas reflexões construídas a partir de uma atividade piloto desenvolvida em uma Escola Estadual de Porto A legre, onde foi exibida aos alunos uma coleção de 127 imagens, divididas em seis temas. Todas as imagens foram retiradas de sites da internet. A lém disso, 0 artigo traz uma descrição da atividade e também algumas considerações a serem feitas para o professor que pretende utilizar esse recurso, no sentido de um melhor aproveitamento.
\end{abstract}

Palavras-chave: Paisagens, Interdisciplinaridade, Ensino de ciências.

* Licenciado em Q uímica, M estre em Educação em Ciências: Q uímica da V ida e Saúde (UFRGS). Técnico em Educação no Grupo H ospitalar Conceição (Porto Alegre) e professor na rede pública estadual do RS. E-mail: julianoguterres@yahoo.com.br

** Licenciado em Química, D outor em Psicologia do D esenvolvimento pela U FR GS. Professor da U niversidade Federal da Bahia (UFBA) e do PPG Educação em Ciências da UFRGS. E-mail: exlerbr@yahoo.com.br

*** Licenciado em Q uímica pela PU CR S, especialista em Ensino de Q uímica pela U CS, D outor em Q uímica de Biomassa pela U FR GS. Professor do Instituto de Q uímica (PPG Educação em Ciências e PPG Q uímica) e Coordenador da Área de Educação Química da UFRGS. E-mail:delpinojc@yahoo.com.br 


\begin{abstract}
A bstract: I n the last years, we had developed a project that aims to employ geosciences to explain fundamental chemistry concepts. In this context, the idea of using natural landscape pictures as a didactical aid for science teachers arose. This research paper highlights some of the considerations made from a pilot activity developed in a State School in the city of Porto Alegre, R S - Brazil. In this pilot activity, a collection of 127 pictures taken from the I nternet and divided into three different themes was displayed to the students. This paper describes the activity and brings some considerations for teachers who intend to employ this kind of activity in order to help these teachers to take a better advantage from the method.
\end{abstract}

Keywords: L andscapes, I nterdisciplinarity, Sciences teaching.

\title{
Introdução
}

O termo paysage poderia ser entendido como a criação da região, do país (pays, em francês). Em português, o sufixo -age ou -agem tem uma função semelhante, como se pode inferir dos termos "montagem" ou "dragagem". Então, por extensão, podese entender a paisagem, também, como 0 ato ou efeito de criar 0 lugar.

Segundo Bertrand (1995), a paisagem tanto pode ser definida como um fenômeno cultural, quanto reconhecida como um fenômeno natural. 0 autor sugere ainda que "a produção de uma paisagem é geralmente considerada como um processo tripolar no qual intervêm um observador, um mecanismo de percepção e um objeto".

Assim, as paisagens antes representadas por pinturas, poemas e outras manifestações artísticas passam a ser representadas, principalmente por fotografias. Para Cueco (1995), as novas noções de paisagem aparecem com o desenvolvimento da imagem, veiculadas pelos meios de comunicação. A utilização da 
fotografia e seus novos meios de divulgação não retiram o caráter artístico da paisagem, pois a captação da imagem através da lente é controlada pelo fotógrafo, que, através desse controle, define a imagem que quer destacar ou esconder.

D onadieu (1995) mostra que somente as fotografias familiares despertam maior interesse que as fotografias de paisagem. Esse interesse pode ser entendido como uma angústia com o desaparecimento real ou anunciado de partes do meio ambiente natural. Esse autor sugere que as emoções diante do espetáculo da natureza selvagem se relacionam com um espírito de contemplação, inspirado por filósofos transcendentalistas, como por exemplo, Ralph Emerson ${ }^{1}$ e H enri Thoreau? ${ }^{2}$.

Enquanto isso, ao analisar as propostas dos PCN 's (Parâmetros Curriculares $\mathrm{N}$ acionais), Bonfim (2006, p. 128) entende que estes:

...têm produzido novas proposições didáticas, mas, na realidade da Geografia escolar o que se tem percebido é que foram ineficazes, isto é, não acompanharam as atividades concretas capazes de responder às necessidades dos professores dos níveis de ensino fundamental e médio.

0 autor sugere ainda que:

o ensino de Geografia se inscreva num paradigma interacionista e sóciocontrutivista, que valorize as aprendizagens significativas e contextualizadas, assim como os raciocínios com características explicativas e interpretativas.

Para M atias (2005), as imagens podem funcionar como uma chave para o pensamento crítico sobre o espaço. D essa forma, 0 autor entende que mapas, gráficos e fotografias são ferramentas não apenas para os profissionais da Geografia ou áreas afins, mas também para os educadores em geral. Através dessas

1 Ralph Waldo Emerson (25 de maio de 1803, Boston, M assachusetts - 27 de abril de 1882, Concord, N ova H ampshire) foi um famoso escritor, filósofo e poeta estadounidense.

2 H enry D avid Thoreau (12 de julho de 1817, Concord - 6 de maio de 1862, Concord) foi um ensaísta, poeta, naturalista e filósofo estado-unidense. 
imagens podemos constatar fatos, fenômenos, eventos geográficos e representar a superfície terrestre.

N esse sentido, o mesmo autor defende que: "as novas tecnologias são recursos do nosso tempo que podem ser empregados de forma inovadora na mediação entre ensino e aprendizagem". M as ele adverte que é preciso saber lidar com as informações on-line. A superação desse obstáculo pressupõe a criação de mecanismos que discutam estratégias de pesquisa, seleção, tratamento e processamento da informação. Ele enaltece as contribuições da informática educativa ressaltando que esta tende a "favorecer o trabalho do professor, enriquecendo e diversificando a sua forma de encaminhar o processo de ensino-aprendizagem".

Para Sauer (1925/1998), um enfoque sobre a morfologia fisiológica das paisagens naturais poderia identificar os materiais e o clima como os principais fatores causais das paisagens. Propõe, também, um estudo da morfologia das paisagens relacionada às condições e características físicas e químicas das rochas. Em relação à química, que é o nosso foco de interesse, por exemplo, cita um estudo que buscou identificar a solubilidade e resistência química das rochas:

as formas da paisagem natural envolvem primeiramente os materiais da crosta terrestreque determinam, em alguma medidaimportante, as formas da superfície. (...) O geógrafo está interessado em saber se a base de uma paisagem écalcário ou arenito, se as rochas são maciças ou intercaladas, se elas são fraturadas ou são afetadas por outras condições estruturais expressas na superfície. Essas questões podem ser significativas para compreensão da topografia, do solo, da drenagem e da distribuição mineral (SAU ER, 1925/1998, p. 40).

V isando uma complementação da afirmação anterior, destacamos que para Brunet (1995),

uma mesma paisagem pode ser analisada em função de diferentes ciências (geomorfologia, botânica, economia, sociologia, etc.) e em função de preocupações (ou pontos de vista) diferentes no interior de uma mesma ciência. 
Por essa razão, entende-se que é possível a utilização de paisagens em atividades didáticas. Bertrand (1995) indica que há uma descoberta da paisagem por um número cada vez maior de disciplinas.

A atividade que será relatada e discutida nesse artigo consiste em um estudo inicial sobre a viabilidade da prática da utilização de paisagens em atividades didáticas na escola básica, não somente contemplando aspectos motivacionais, mas subsidiando discussões e recursos para o professor contemplar os conteúdos propostos pelas disciplinas curriculares.

\section{Contextualização do ambiente e dos sujeitos}

A atividade descrita neste artigo foi desenvolvida em uma Escola da rede pública estadual, localizada na Z ona N orte de Porto A legre. A Escola atende a uma clientela de alunos oriundos das classes média e baixa, cujo perfil se altera de acordo com 0 turno de funcionamento. Enquanto o turno da manhã éfreqüentado regularmente, com baixos índices de evasão e vem formando nos últimos anos alunos de desempenho destacado nos concursos vestibulares e no Exame $N$ acional do Ensino M édio (ENEM), o turno da noite tem altos índices de evasão, baixo desempenho dos alunos em concursos externos e mesmo nas avaliações internas das disciplinas. A lém disso, o turno da noite é formado quase integralmente por alunos repetentes e com histórico de baixo aproveitamento escolar. R ecentemente, tem aumentado a preocupação por parte de direção e de professores do noturno com a violência e o consumo de drogas na região e na Escola.

0 grupo de alunos que participaram da atividade que será analisada era de uma turma de primeiro ano do ensino médio noturno. No início do ano letivo, a turma contava com uma média de vinte alunos freqüentes, tal como a média das demais 
turmas da Escola. Ao longo do primeiro trimestre, a freqüência do turno caiu praticamente pela metade. Com isso, e por uma decisão da Secretaria da Educação/R S, algumas turmas foram reunidas, ou, utilizando o mesmo termo vinculado na imprensa local a respeito da decisão do governo, foram "enturmadas". A "enturmação" reuniu duas turmas de primeiro ano e trouxe algumas rivalidades entre os grupos já existentes. A sala com mais pessoas trouxe mais motivação aos alunos, principalmente os mais velhos, para continuarem os estudos. No entanto, as rivalidades entre os grupos começaram a atrapalhar o andamento das aulas e isso aumentou significativamente a evasão escolar. N o segundo semestre do ano, a turma se estabilizou com pouco mais de dez alunos freqüentes.

Tais fatores prejudicaram o andamento do conteúdo programático em algumas disciplinas, dentre elas a química, disciplina em que foi proposta a atividade discutida neste artigo. Porém, isso não impediu que os alunos aproveitassem a atividade com as paisagens para construir algumas relações entre as imagens observadas e a matéria estudada em sala de aula. Talvez porque muitos do grupo não estavam cursando o primeiro ano pela primeira vez.

Essa atividade aconteceu na última semana letiva, uma semana após a avaliação trimestral. O conselho de classe final, que definiria as aprovações e reprovações aconteceria naquela semana, o que pode explicar uma motivação extra de alguns alunos. M esmo sabendo que o trabalho com as paisagens não teria participação na avaliação, sete alunos compareceram para a atividade. As características e objetivos do trabalho não foram previamente explicados, mas foi avisado que aconteceria uma atividade diferenciada, sem avaliação no último encontro com a turma.

As características da proposta, reações dos sujeitos e discussões sobre possibilidades de trabalho serão temas da seção seguinte deste trabalho. 


\section{Resultados e discussões}

Por se tratar de um estudo exploratório acerca da validade desse tipo de atividade, a proposta para seu desenvolvimento não fora previamente estruturada. Os alunos foram convidados a observar as coleções de paisagens, todos ao mesmo tempo, diante de um computador. O objetivo era provocar discussões em grupo na medida em que fossem surgindo assuntos ou dúvidas. Toda a atividade foi registrada através da webcam de outro computador e transcrita para posterior análise.

As imagens foram obtidas, principalmente, em sites específicos, como o trekearth.com, que é voltado à aprendizagem do mundo através de imagens, e como o flickr.com, que é voltado à apresentação e organização de fotografias, principalmente de amadores. A vantagem desse segundo é o incentivo para que os usuários disponibilizem suas fotografias sob o critério copyleft, ou seja, que as imagens possam ser utilizadas, copiadas e distribuídas, citando o autor da mesma. ${ }^{3}$

As imagens foram agrupadas em seis categorias, divididas por temas:

- Vulcões: compilada a partir de paisagens vulcânicas indicadas nos livros de Bourseiller e D urieux (2001), K raft (1991), Pradal e D ecobecq (2004) e Press e colaboradores (2006), essas imagens permitem apresentar aos alunos al guns processos geológicos de formação das paisagens, rochas e minerais, associados ao magma e seu resfriamento.

- Lagos vulcânicos: permitem apresentar alguns princípios biogeoquímicos relacionados à coloração dos lagos, buscando a justificativa para suas mudanças de cores.

- Salinas: seguindo o propósito de percepção e de identificação de processos biogeoquímicos associados às paisagens, nesta categoria o objetivo é explorar a produção de sais, especialmente

N as imagens apresentadas neste artigo, apresenta-se o apelido dos usuários de Flickr.com e Trekearth.com, conforme o cadastro que eles realizaram junto à ferramenta. 
do cloreto de sódio $(\mathrm{N}$ aCl) e a atração turística vinculada às regiões onde esses processos acontecem.

- Montanhas: nesta seqüência de imagens, o objetivo é mostrar a variedade de cores e formas apresentadas pelas formações montanhosas da superfície terrestre. Além disso, essas imagens evidenciam o tipo de exploração econômica dessas regiões, principalmente em relação ao turismo e comércio de pedras.

- M ineração: essas imagens permitem evidenciar os processos de extração e o impacto ambiental deste tipo de exploração. Também permitem uma ampliação da compreensão dos ciclos biogeoquímicos a partir da observação das cores percebidas durante o processo, nos produtos e nos resíduos.

- Fumarolas: as imagens presentes nessa categoria permitem a particularização da exploração do enxofre em regiões vulcânicas. Além disso, as imagens evidenciam as condições de trabaIho dos mineradores, a insalubridade do local devido à presença de vapores tóxicos e a pobreza da região, denunciando a desigualdade social em contraste com a realidade das indústrias que, com o enxofre extraído, produz ácido sulfúrico.

No início, alguns alunos pareciam querer mostrar uma participação mais efetiva, sentaram-se próximos ao computador e falavam espontaneamente em todas as imagens. Talvez por entenderem que uma participação positiva na atividade pudesse alterar a situação deles no parecer final do conselho de classe. Porém, seus comentários eram desinteressados e óbvios. N ão estavam, realmente, sendo instigados pelas imagens. O s demais se mostravam acanhados. Pareciam receosos em cometer algum erro e que, novamente, isso influenciasse negativamente sua situação no parecer do conselho de classe. Aos poucos, as imagens começaram a impressionar o grupo e o interesse incentivou a discussão.

A primeira seqüência de imagens traz fotos bastante expressivas sobre vulcões e erupções de diversas regiões do mundo. Isso contribuiu positivamente para motivar os alunos a participarem das demais atividades. 


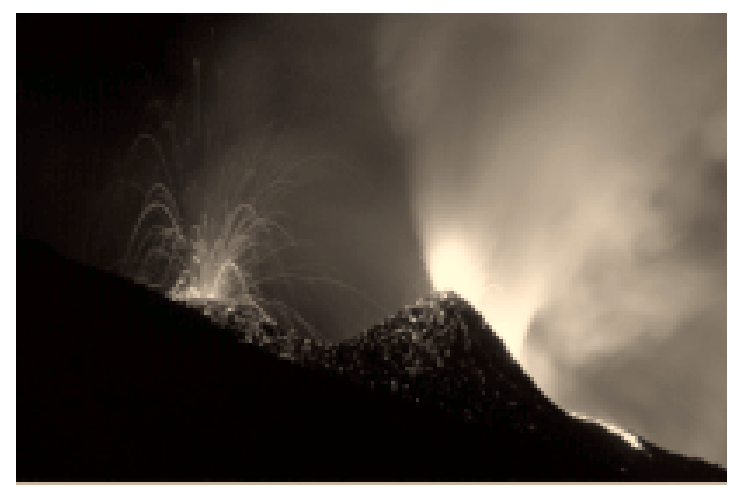

(a) Fonte: Thomas R eichart (FlickR .com)

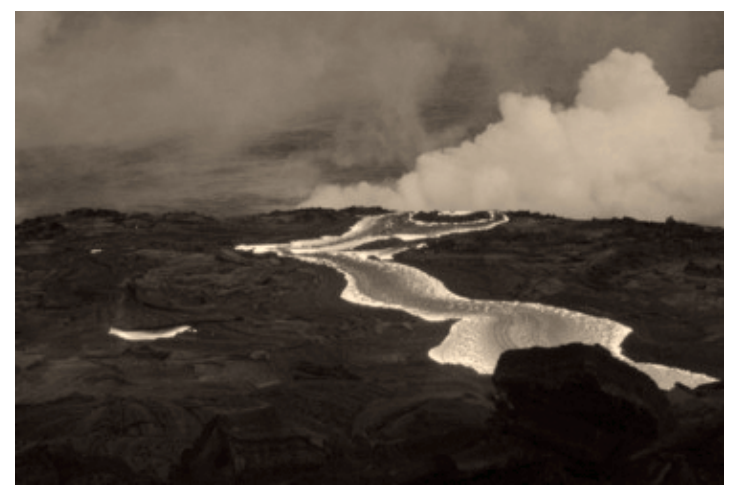

(b) Fonte: xraydeltaone (FlickR.com)

Fig. 1: Exemplos de imagens presentes na primeira seqüência de imagens: alunos ficam impressionados.

O primeiro assunto a cativar o grupo foi o das altas temperaturas das lavas vulcânicas e a destruição deixada por onde passa. Esse momento pareceu ser bastante apropriado para 0 desenvolvimento de um trabalho interdisciplinar. Os aspectos relacionados aos vulcões, tais como explicações acerca da formação geológica, histórico das grandes erupções, influências econômicas e políticas e a interpretação de outros povos para o fenômeno (cultos, deuses, crenças). 
Em seguida, ainda na mesma seqüência de imagens, chama ram a atenção dos alunos as fotografias de gêiseres em regiões vulcânicas (Fig. 2). M ais uma vez, a temperatura estava na pauta das discussões e das perguntas. Em um dado momento, um dos alunos afirmou que a temperatura da água superava os $3000^{\circ} \mathrm{C}$. N esse momento, o professor intervém no diálogo:

Professor: Será que étão quente assim? Porque aquela lava que nós estávamos vendo antes provavel mente esteja acima de $3000^{\circ} \mathrm{C}$ para derreter as pedras. M as sea água ainda estálíquida, ésinal que não ultrapassou os $100^{\circ} \mathrm{C} . .$.

Aluno: Ah é, depois ela evapora, né?

Professor: Então não étão quente assim. É água fervendo. O lhem aquela "fumacinha"...

Aluno: Aquilo é água fervendo?

Professor: Já está fervendo...

Aluno: Mas quanto tempo deve durar?

Professor: D epende do tamanho, da quantidade de água...

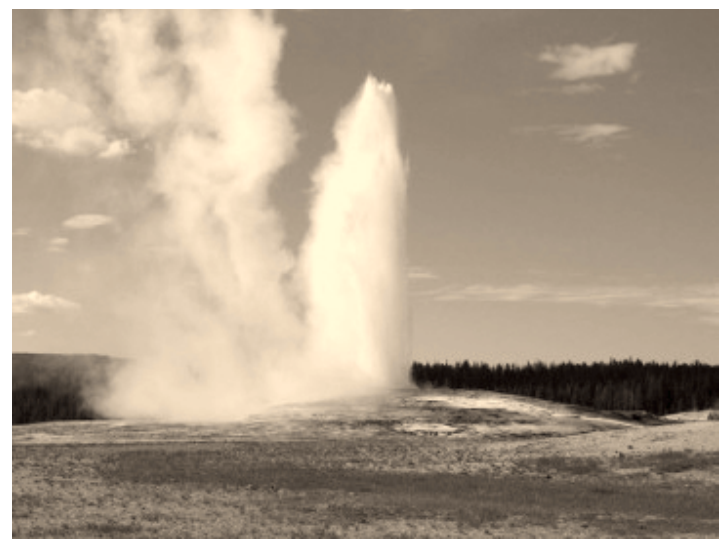

(a) Fonte: mikepj (Flickr.com) 


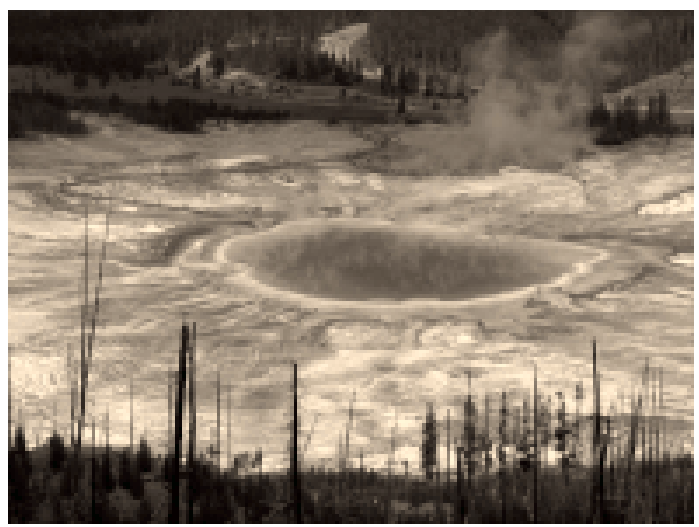

(b) Fonte: M agadelic Rock (Flickr.com)

Fig. 2: I magens de gêiseres no parque Yellowstone, nos Estados U nidos: alunos demonstram interesse em fenômenos naturais que não fazem parte da realidade do ambiente deles.

J untamente com a questão da temperatura, outras surgiram nas discussões, como aquelas relativas às varias cores presentes na água e no solo das regiões mostradas nas fotos (Fig. 3). Essa questão esteve presente também na seqüência de imagens seguinte, com uma coleção de imagens relacionadas aos lagos vulcânicos. 0 tema é rico em possibilidades de assuntos relacionados à área de conhecimento de ciência e que podem ser abordados em sala de aula.

Influenciados pela exibição das imagens anteriores, os alunos atribuem a causa dessas cores à temperatura e à presença de lava vulcânica. Esse é outro aspecto que pode ser pensado pelo professor no momento da montagem da atividade: considerar que as primeiras fotos irão influenciar na interpretação das seguintes. Ainda mais se houver interferência do professor/pesquisador, como foi o caso. N esse sentido, é importante o conceito de "esquemas familiares" utilizado em pesquisas microgenéticas de resolução de problemas (IN H ELDER; CELLÉR IER, 1996). O sujeito interpretará a situação de acordo com o que suas experiências prévias lhe permitem. No momento em que ocorrer a 
"descristalização" do esquema familiar o sujeito então poderá atingir um patamar cognitivo superior, modificando, decompondo e integrando seus esquemas (BODER, 1996). Isto é, quando o sujeito toma consciência do que existe em sua interação com os objetos, no caso, com as imagens de paisagens, pode entender que sua explicação não serve mais para o que seus olhos vêem.

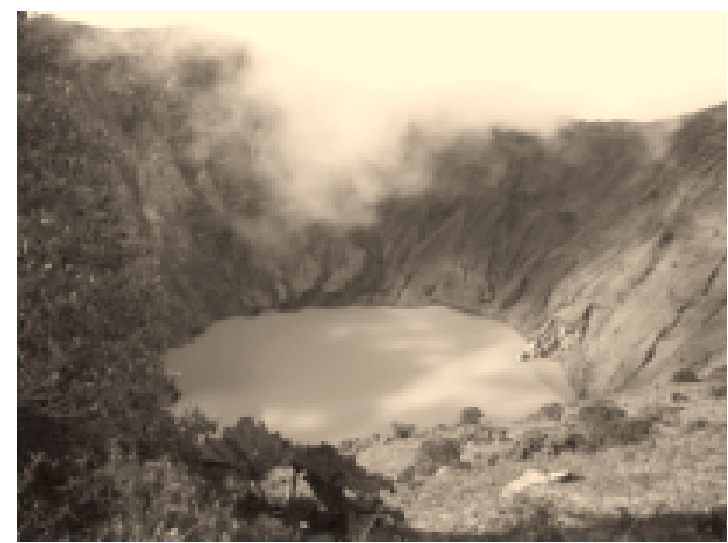

(a) Fonte: M arianela Jaramillo (eva_luna) (TrekE arth.com)

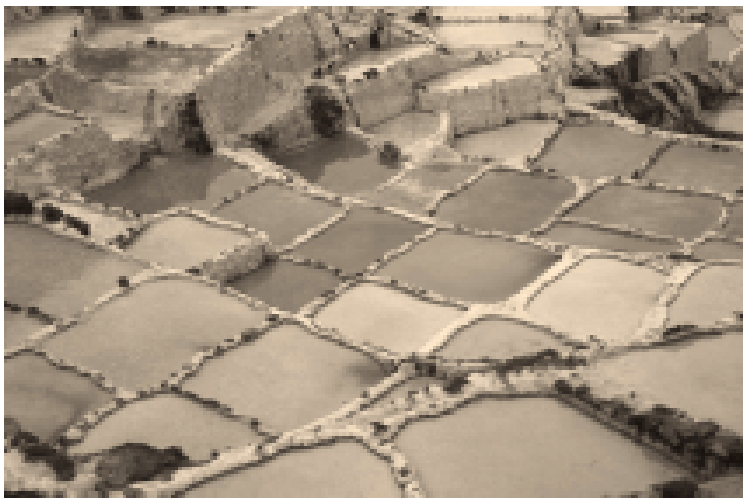

(b) Fonte: foto_morgana (FlickR .com)

Fig. 3: I magens pertencentes à segunda seqüência de imagens: alunos se mostram interessados pelas cores. 
Construindo esquemas novos, o sujeito tenderá a testar seus novos esquemas. Jogar com eles, exercitar, aplicá-lo a novas situações, tentando assimilar novas informações a ele (PIAGET, 1990). O professor, no momento de planejar uma atividade dessa natureza, deve mostrar imagens que problematizem os assuntos de seu interesse e dos alunos.

A explicação das cores em paisagens pode se constituir em tema rico e amplo a ser pesquisado. A pós uma breve discussão entre os participantes, um aluno afirmou em tom de suposição: "deve ter um produto químico dissolvido nessa água". A Grande Fonte Prismática (Fig. 2b), localizada no Parque Yellowstone nos Estados U nidos tem como causa de suas lindas cores os chamados "ciclos biogeoquímicos", onde as cores não dependem somente das substâncias químicas ali dissolvidas, mas também da concentração, acidez e temperatura. Essas condições favorecem o desenvolvimento de determinadas algas que por sua vez alteram as cores e as condições físico-químicas citadas. Assim, podemos perceber que 0 assunto é bastante complexo. Para sua compreensão faz-se necessário a utilização de conceitos de diversas áreas como físico-química, biologia e geologia. Especificamente para a química do ensino médio poderia se desenvolver a partir dessa questão assuntos como a solubilidade de alguns sólidos iônicos em água; a influência da temperatura na solubilidade; as propriedades coligativas e suas variações; o conceito de pH e seus indicadores; o equilíbrio químico e os fatores de deslocamento, entre outros.

D urante a discussão de algumas das imagens do terceiro eixo de paisagens, que envolve as salinas, onde se exibe pequenos volumes de água com diferentes cores, como na Fig. 3b, uma aluna comentou que "parece aquele negócio do M arrocos, que eles usam para tingir roupas". Ao que outro discorda: "isso aí é um pesque-pague. Deve estar cheio de peixes." $N$ ão se pode esquecer a contextualização daquilo que está sendo trabalhado a partir das interpretações dos alunos. No entanto, pode ser necessário desconstruir alguma(s) ideia(s) equivocada(s) eesse é o papel 
do professor. N ão se pode negar a importância, dentro do processo de aprendizagem desses sujeitos, da busca por explicações para os fenômenos percebidos nas imagens. Contudo, isso não pode ser tomado como suficiente para uma compreensão científica do objeto. M uitas das interpretações sugeridas pelos sujeitos são de senso comum, reflexos das suas experiências prévias. Essas interpretações são importantes para a construção de novos conceitos - que é o objetivo de uma atividade escolar, mas é necessário que se criem conceitos novos, se construa relações novas. Se isso não ocorrer, o sujeito limita-se a assimilar novas informações àquilo que el ejá conhecia, sem qualquer evolução cognitiva. Assim como não é desejável que o sujeito construa um novo conceito e o estenda a todos os outros fenômenos. Essa é a própria definição de um tipo comum de "obstáculo epistemológico" definido por Bachelard, o reducionismo do conhecimento unitário ou pragmático.

D urante a visualização das imagens do eixo "mineração", destaca-se a seqüência de fotos referentes à extração de cobre a partir de seus minérios, conforme Fig. 4. Esta seqüência traz imagens que mostram as diversas fases do processo.

A questão das cores pode ser mais bem explorada a partir do estudo das colorações diferentes produzidas na dissolução de sais de diferentes metais de transição. $\mathrm{N}$ a Fig. 5 vemos imagens de soluções de diferentes sais à esquerda e ao lado uma amostra de cobre nativo. Podemos perceber a relação entre as cores das imagens da mineração do cobre e da solução azulada obtida em laboratório através da dissolução do sulfato de cobre.

O utra seqüência de imagens que também impressionou bastantefoi a do acúmulo de enxofre ao redor dos vulcões, conforme Fig. 6.

Professor: Enxofre! I sso aí é enxofre puro!

Alunos: O hhh...

Professor: E aquela fumacinha ali...

Alunos: Isso que eu ia falar... D eve ser tri fedida... 
Professor: Essas fumaças aí, além de extremamentefedorentas, pois tem cheiro de bicho morto, fazem muito mal para a saúde. M as pensem nisso: quando a carneapodrece, o cheiro ruim quesentimoséo cheiro do enxofre. O u melhor, do gás sulfídrico.

Alunos: M as porque aquela fumaça? É o calor?

Professor: quando tem umidade, com o calor... 0 enxofre reage com a água e forma outras substâncias. D aí o gás sulfídrico...

Alunos: Ah... To ligado...

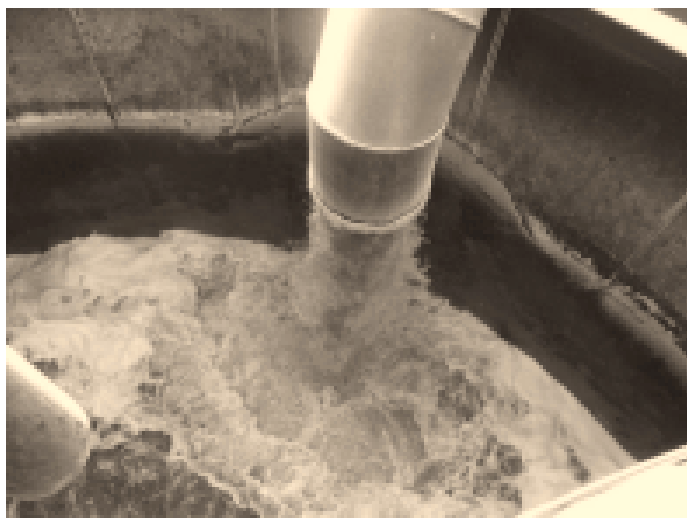

(a) Fonte: Gayle H anssen (Pbase.com)

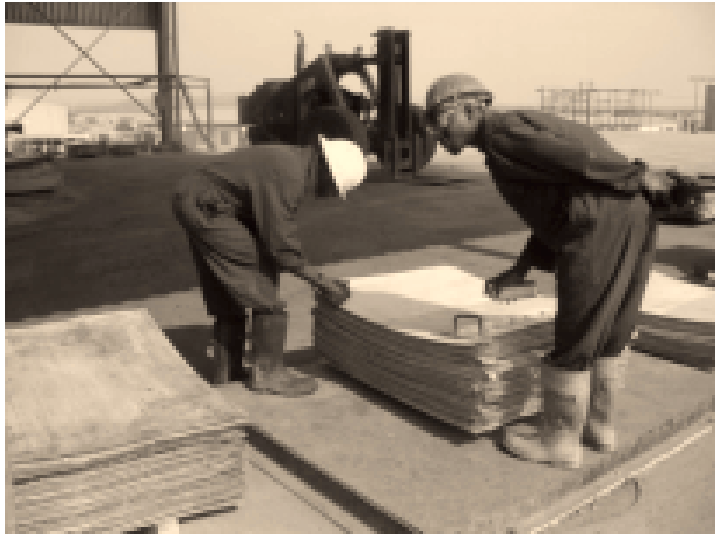

(b) Fonte: Gayle $\mathrm{H}$ anssen (Pbase.com)

Fig. 4: I magens sobre mineração do cobre: relação com as cores observadas em soluções de laboratório. 


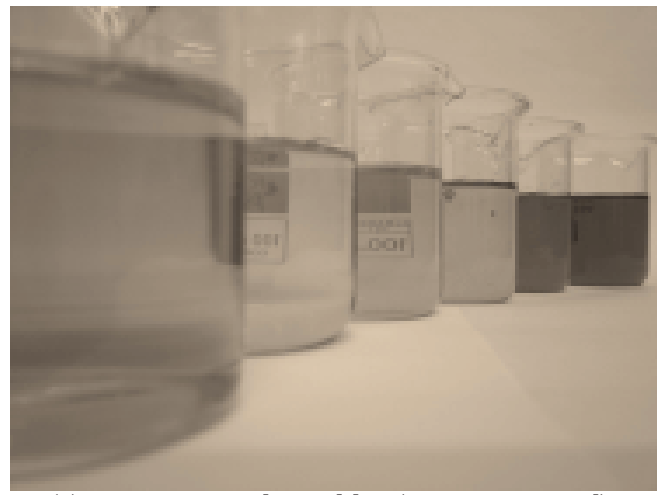

(a) Fonte: M arcelo Eichler (arquivo pessoal).

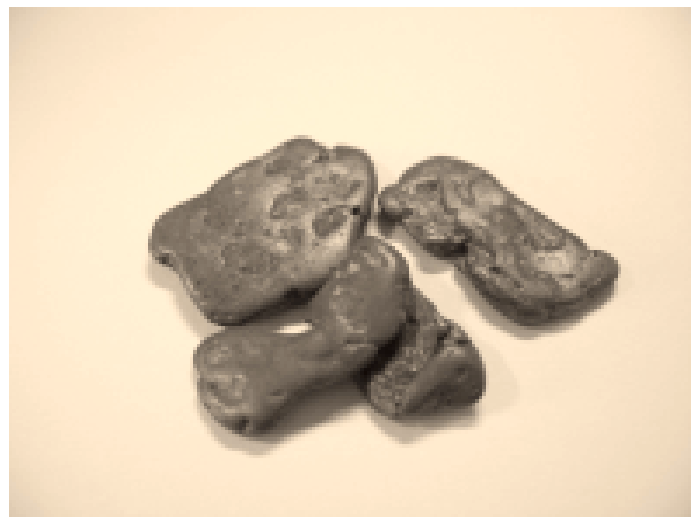

(b) Fonte: Juliano Guterres (arquivo pessoal).

Fig. 5: N a primeira imagem, soluções de diversos sais. $\mathrm{N}$ a segunda, amostras de cobre nativo.

A lém das discussões acerca das questões científicas, algumas dessas imagens podem servir de subsídio para discussões que transcendam, não só a área da química, mas as ciências como um todo. Este éo caso de algumas fotos presentes nos eixos "M ontanha", "M ineração" e "Fumarolas" (Fig. 7). N essas paisagens se observa o contraste das realidades sociais: por um lado, lugares atrativos para o turismo, pessoas belas e felizes passeando por 
lugares exóticos. De outro, trabalhadores em situações de quase escravidão obrigados a trabalhar em condições precárias, insalubres e miseráveis. 0 extrativismo tem ainda o lado daqueles que financiam a extração e lucram exportando, muitas vezes ilegalmente, as pedras de uma região.

Mais uma vez discussões dessa natureza podem fazer parte de projetos interdisciplinares envolvendo G eografia, Q uímica, Biologia e H istória, por exemplo. U ma sugestão de atividade é procurar situações semelhantes em regiões brasileiras. Estudar diversos aspectos relacionados à extração, comércio, exportação e exploração de pedras preciosas (gemas) nos estados produtores no Brasil (por exemplo, M inas Gerais, Bahia e R io Grande do Sul).

A atividade teve duração de aproximadamente cinqüenta minutos (um período) onde foram exibidas 127 imagens, divididas em seis eixos temáticos. Segundo relatos dos alunos, a atividade foi agradável e interessante. Entendemos que atividades desse gênero são bastante proveitosas e que se faz necessário uma reflexão sobre o planejamento e o objetivo dessas para obter um maior aproveitamento do espaço e do tempo escolar.

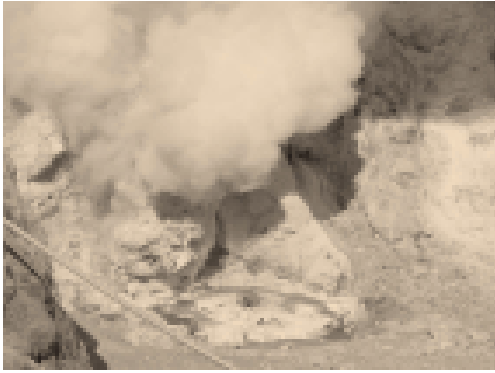

(a) Fonte: J eanie Barnett (FlickR.com)

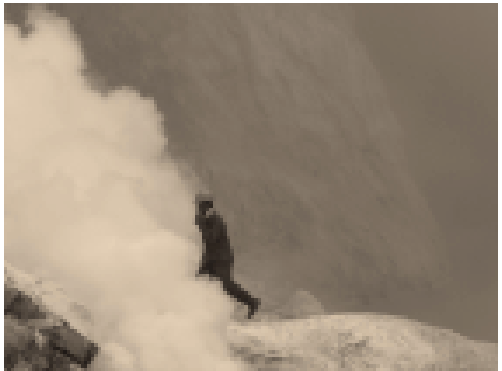

(b) Fonte: whenandwhere (FlickR.com)

Fig. 6: As imagens do enxofre e a atividade econômica vinculada a ele foram objeto de discussão. 


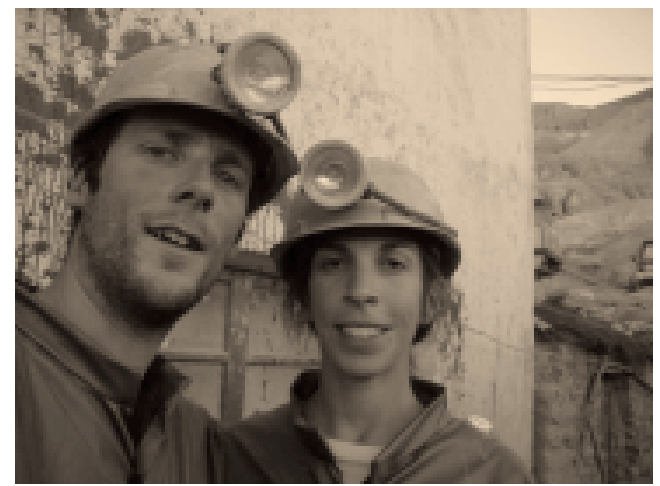

(a) Fonte: caroline.nuffort (FlickR .com)

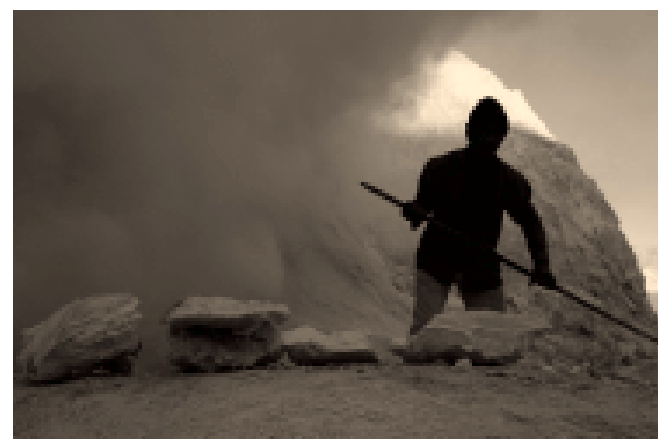

(b) Fonte: egypety (FlickR .com)

Fig. 7: Q uestões sociais também podem ser abordadas a partir de imagens como estas.

\section{Considerações finais}

Por tudo que foi explicitado sobre as características desses alunos, da Escola e dos problemas ocorridos ao longo do ano, consideramos que a avaliação de uma atividade dessa natureza deve ser positiva. Entendemos que a proposta deve ser aperfeiçoada para um melhor aproveitamento das imagens e do tempo disponível. 
A lgumas medidas, no sentido de aumentar o envolvimento dos alunos, poderiam ser consideradas para transformar essa atividade piloto em um projeto interdisciplinar:

- Proposição de temas para pesquisa bibliográfica: durante os debates os alunos acenam com muitas dúvidas. De acordo com o interesse de cada um, as imagens podem estimular 0 interesse em muitos assuntos diferentes. U ma estratégia de trabalho seria propor que os alunos façam uma pesquisa com os temas que lhes causaram algum impacto, buscando e apresentando explicações para os fenômenos observados.

- Alunos trazendo imagens: a partir de uma atividade como esta, poderia se propor que os alunos buscassem imagens de paisagens que Ihes chamassem a atenção em determinados aspectos.

- Trabalhar com técnicas de fotografia: os alunos podem ter interesse na fotografia em si e menos no seu objeto. Poderia se pensar em uma atividade que proporcionasse aos alunos a oportunidade de aprender a fotografar paisagens. Trabalhar algumas técnicas básicas de fotografia, como velocidade de obturador, abertura do diafragma, foco, profundidade de campo, padrões de cor, etc.

- Envolvimento das Artes e da H istória: muitas vezes nas aulas de ciências não se tem muitas oportunidades de relacionar os assuntos estudados aos conteúdos dessas áreas do conhecimento. Essa oportunidade aparece ao se fazer uma atividade dessa natureza. Algumas pinturas e textos históricos tratam de uma representação de fenômenos naturais, como erupções, por exemplo, e também podem ser utilizadas dentro de um projeto interdisciplinar.

- Estimular o interesse por museus de ciências naturais: havendo possibilidade de se fazer uma saída de campo, essa seria uma oportunidade. A proveitando o interesse surgido a partir das discussões das paisagens, uma visita a um museu poderia fomentar diversos assuntos que podem ser discutidos nas aulas, como o processo de fossilização, por exemplo. 
É necessário enfatizar que essa atividade pressupõe um planejamento por parte do professor, como fora destacado no decorrer do texto. 0 planejamento tem que prever que alguns conceitos prévios deverão ser modificados para a construção de novos conceitos. D eve contemplar, também, formas de evitar que alguns conceitos construídos se apliquem, de maneira geral, a outros fenômenos, numa tentativa de atribuir a objetos diferentes a mesma explicação científica, mas disparatada. Por exemplo, existem diversos motivos relacionados aos diferentes tons de azul ou de verde das águas. É preciso conhecer as situações em que há a mineralização, para reconhecer que o tom de azul turquesa se deve a altas concentrações de cobre. Além disso, como vimos anteriormente, em uma atividade dessa natureza, podemse buscar explicações relacionadas a diversos níveis de especialização nas áreas do conhecimento. I sso significa que, de acordo com o planejamento, a atividade pode ser útil em diferentes níveis de ensino.

\section{Referências}

BACH ELARD, Gaston. A formação do espírito científico: contribuição para uma psicanálise do conhecimento. $R$ io de janeiro: Contraponto, 1996.

BERTRAND, Georges. Le paysage, entre la nature et la société. In: RO GER, Alain. (Ed.). La théoriedu paysageen France(1974-1994). Seyssel: Champ Vallon, p. 88-108, 1995.

BODER, A ndré. "E squema familiar": a unidade cognitiva de procedimento preferida. In: IN H ELDER, Bärbel; CELLÉRIER, Guy (Ed.). $O$ desenrolar das descobertas da criança: um estudo sobre as microgêneses cognitivas. Porto alegre: Artes M édicas, 1996.

BO N FI M , N atanael R eis. Geografia escolar: qual o seu problema? Caminhos de Geografia. U berlândia, v. 7, (18), p. 123-133, 2006.

BO U R SE I L LER, Philippe; DU RIEU X, Jacques. D esvolcanset deshommes Paris: Editions de la M artinière, 2001. 
BR U N ET, R oger. A nalyse des paysages et semiologie - élements pour un débat. In: R O GER Alain (Ed.). La théoriedu paysageen France(19741994). Seyssel: Champ Vallon, p. 7-20, 1995.

CU E CO, H enri. A pproches du concept de paysage. In: R O GER Alain (Ed.). L a théoriedu paysageen France(1974-1994). Seyssel: Champ Vallon, p. 168-181, 1995.

DONADIEU, Já Pierre. Pour une conservation inventive des paysages. In: R O GER Alain (Ed.). La thériedu paysageen france(1974-1994). Seyssel: Champ Vallon, p. 400-423, 1995.

IN H ELDER, Bärbel; CELLÉRIER, Guy. O desenrolar das descobertas da criança: um estudo sobre as microgêneses cognitivas. Porto Alegre: Artes M édicas, 1996.

KRAFT, M aurice. L esfeux dela terre- histoiresdevol cans. Paris: Gallimard, 1991.

M ATIAS, Vandeir Robson da Silva. As relações entre geografia, mediação pedagógica e desenvolvimento cognitivo: contribuições para a prática de ensino em geografia. C aminhos de G eografia, v. 24 (17), p. 250264, 2005.

PIAGET, J ean. A formação do símbolo na criança: imitação, jogo e sonho. I magem e representação. R io de janeiro: LTC, 1990.

PRADAL, Evelyne; DECO BECQ , D ominique. Au coeur des volcans. Paris: Fleurus, 2004.

PRESS, Frank; SIEVER, R aymond; GR OTZIN GER , John; JOR DAN, Thomas H. Para entender a terra. Porto A legre: Bookman, 2006.

SAU ER , Carl. A morfologia da paisagem. In: COR R ÊA R oberto L obato; R OSEN D AH L , Zeny (Ed.), Paisagem, tempoecultura. R io de aneiro: EdU erj, p. 12-74, 1998. (Trabalho originalmentepublicado em 1925) 